Crianças na psicanálise - clínica, instituição, laço social Angela Vorcaro Rio de Janeiro, Companhia de Freud

\title{
Crianças na psicanálise
}

\author{
Marciela Henckel
}

\begin{abstract}
Angela Vorcaro é psicanalista, ${ }^{1}$ com vasta experiência no trabalho e estudo sobre crianças, que vem, por meio deste livro, apresentar uma admirável diversidade de questões referentes à clínica com crianças, com base em diferentes lugares. Seu percurso se realiza a partir da pergunta sobre a posição desta especificidade clínica relativa à clínica psicanalítica e à formação do psicanalista; prossegue referindo-se ao lugar do psicanalista no trabalho que se pretende em equipe ou, mais ainda, no trabalho interdisciplinar, trazendo a experiência de uma intervenção numa instituição escolar; e, finalmente, traz uma importante elaboração sobre o discurso psicopedagógico e as interrogações que este discurso pode fazer ao psicanalista e este à psicopedagogia - especialidade que teve uma grande difusão de cursos de formação nos últimos dez anos.
\end{abstract}

1. Angela Vorcaro exerce atividades clínicas e didáticas na PUC-SP, participa de um projeto de pesquisa do Instituto de Estudos da Linguagem da UNICAMP, é autora do livro $A$ criança na clínica psicanalítica. 
A autora baseia-se num referencial freudiano e lacaniano, aos quais parece demonstrar-se convocada com base nas reflexões mesmas suscitadas pela prática analítica, mais especificamente aqui, questões que a clínica de crianças impõe - por exemplo, sua condição de ser em constituição; as resistências que ela mobiliza, dado o reencontro do analista com a sua criança recalcada e com o real, conforme aborda Lacan, que parece incidir privilegiadamente, segundo a autora, na clínica com crianças.

Tratar uma criança, conforme nos aponta A. Vorcaro, além de responsabilizála pelo seu sintoma - condição para que a criança se constitua como sujeito de sua própria palavra -, implica “... virar o método analítico ao avesso: emprestar-lhe desejo, significantes e imaginário, para que ela possa experimentar e constatar a possibilidade de sair das determinações do campo da linguagem em que está imersa, através do seu ato de fala" (p.13). É o que se faz necessário no trabalho com crianças acometidas por graves psicopatologias, especificidade que recorta a presente produção.

No primeiro capítulo, intitulado "Da holófrase e seus destinos", Vorcaro retoma o texto de Jacques Lacan, de 1964, Livro 11, sobre as operações de causação do sujeito, para repensar as graves psicopatologias da criança pequena. Na primeira parte, busca esclarecer a leitura que faz das operações lógicas de alienação e separação, para tentar fazer trabalhar esses conceitos, desdobrando-os. Estará apresentando alguns casos clínicos (fragmentos) e discutindo a intervenção do analista na constituição do sujeito - “... tarefa que nos confronta ao limite da capacidade operatória da psicanálise e a direção do tratamento, nas condiçôes que o autismo, as psicoses, a debilidade, o déficit orgânico e as lesões imaginárias impõem a crianças que se situam no limbo entre o ser vivo e o sujeito" (p.19).

Com base nos conceitos de Sujeito, linguagem, Outro, desejo, e das interrelaçōes entre eles, vislumbra-se, aos poucos, uma concepção de constituição psíquica em que a linguagem, precedente ao Sujeito, ${ }^{2}$ " “... é tudo de que a criança dispõe inicialmente para concernir-se; antes de poder contar ou reconhecer os outros que a precedem. A criança imputa à falação, em que está imersa, um querer a ela dirigido e tenta localizar esse querer na sua escalada subjetiva. Só num tempo logicamente segundo, este ser, que será falante, suporá um Sujeito de um tal desejo..." (p. 21). O desejo do Sujeito estaria concernido ao Sujeito do desejo, representado ou, quem sabe, 'encorporado' pelo Outro - atributo desse desejo. Tomando por base articulações como essas, pretende-se esclarecer as relações entre o ser vivo e a linguagem; esta linguagem que perverte a natureza do ser. Para tal, a autora toma

2. O "Sujeito" aqui não se refere ao sujeito psicológico; conforme a autora, "O Sujeito é o efeito da divisão própria ao funcionamento da linguagem, portanto, não pré-existe a ela”, p. 20. 
como referência Contardo Calligaris, quando este trabalha a "Hipótese sobre o fantasma na cura psicanalítica".

Após a definição dos operadores constituintes do sujeito trabalhados por Lacan - alienação e separação -, os quais operam interligados, visto que a separação somente pode ocorrer a partir de uma alienação inicial, a autora vai trazer a idéia da holófrase, que se caracterizaria justamente por uma disjunção nas operações de alienação e separação. Na holófrase, a separação pode não ter acontecido. Introduzem-se aí uma série de casos, nos quais observamos a existência da holófrase, implicando a inexistência de um sujeito dividido: psicose - debilidade - fenômenos psicossomáticos. A autora acrescenta o autismo, considerando que também aí "... há entrada do sujeito na linguagem, como suas manifestações holofrásicas atestam" (p. 27). Em cada um dessas séries há que se considerar os modos pelos quais a criança é conduzida a se situar em relação ao Outro. Antes de adentrarmos nas especificidades da série, ou seja, do que se passa no autismo, na psicose etc., voltemos um pouco mais nossa atenção para a noção de holófrase.

Baseando-se nos escritos de Alexandre Stevens, a autora apresenta um breve desenvolvimento da história da lingüística que incide sobre a idéia da holófrase em diferentes tempos, abordando, finalmente, os distintos momentos da holófrase na obra de Lacan. Este parece ter recebido a influência de G. Guillaume - décadas de 1940 e 1950 -, para quem a holófrase corresponderia a um momento em que a apreensão frásica e a apreensão lexical se confundiriam, ou então, a holófrase definida como ato de linguagem no qual o ato de representação (a língua) e o ato de expressão coincidiriam (p. 30). Vale destacar aí as diferentes abordagens referentes à origem da linguagem, entre elas a de Lamarck e Darwin, teoria evolucionista, que buscavam comparar estruturas e elementos, tentando explicar o passo do animal ao homem, concebendo a idéia de que a linguagem teria natureza instintiva, em continuidade com a expressão inata das emoções (p. 30). Aqui, a holófrase corresponderia ao estágio intermediário entre o grito expressivo animal e a linguagem humana.

Lacan vai dar um destino diferente ao termo holófrase, a partir das torções sobre a sua noção lingüística. Um destino que vai se fazendo ao longo de diferentes momentos de sua obra, apresentados por Vorcaro. Destacamos a noção última em que ele trata a holófrase como o nome dado à ausência da dimensão metafórica: "A solidificação do primeiro casal de significantes impede que um significante possa vir no lugar do outro, já que eles ocupam o mesmo lugar. O primeiro casal de significantes é aquele que determina a divisão..." (p. 33). E mais: "Na ausência de intervalo entre S1 e S2, o desejo do Outro não aparece ao sujeito na falha em que ele seria interrogável, mas como um gozo do Outro cujo objeto é o sujeito" (p. 34).

Pergunta, então, a aưtora: "Como distinguir, na série de casos em que a holófrase se manifesta, as posições subjetivas?" 
Destacamos alguns pontos de cada caso que tentam dizer algo de uma distinção entre eles. Assim, no autismo, "a criança entra na alienação significante para, a seguir, destacar-se, sem entretanto efetuar uma interpenetração entre os campos do ser (o sujeito) e do Outro (o sentido)" (p. 34). Brevemente, a autora traz as hipóteses sobre o autismo de Lefort, Jerusalinsky, Calligaris e Balbo. Este último nos ensina a idéia da falta do tempo no autismo e, juntamente com J. Bergès, postula a idéia de que o autismo seria uma perversão. Com relação à psicose, destacamos que a criança não encontra, "... no intervalo entre significantes, o ponto de corte em que pode alojar sua perda no desejo do Outro. (...) A criança fica colada ao mandato em que ela é o que falta no Outro" (p. 36). A diferença da debilidade para psicose estaria no fato de que a criança na debilidade não encarna a falta do Outro, porque a este nada faltaria. "A criança identifica-se apaixonadamente ao lugar do verdadeiro, de que está convicta, sem dialetizar o sentido, por não poder suspender ou duvidar do saber do Outro" (p. 38). Já nos fenômenos psicossomáticos, um Outro está em questão, porém este Outro é o próprio corpo, há uma identificação à lesão do Outro (p. 40).

Para finalizar a apresentação deste primeiro capítulo, consideramos muito importante destacar sua hipótese de trabalho na clínica com crianças, baseando-se na pergunta sobre as operações de alienação e separação: Vorcaro diz que elas nos intimam a que saiamos da posição de espera para intervir, elas nos intimam a que nos incluamos a nós mesmos no tratamento. "Elas permitem, ainda, constatar que, na clínica, não existem casos puros dessas categorias, de modo que suas brechas, suas bordas, seus intervalos orientam a hipótese de uma estrutura não decidida. $\mathrm{O}$ não decidido da criança implica a impossibilidade de fazer equivaler a estruturação de uma criança à estruturação do adulto. Assim, a incidência de nossa fala pode mudar o modo de gestão do gozo dessas crianças" (p. 41).

O segundo capítulo, que se refere à transferência na clínica com crianças, inicia com o levantamento de duas questões, com as quais a autora busca uma aproximação do estatuto da transferência como meio de tratamento na clínica com crianças: "Como ler as manifestações de uma criança? Qual é a direção do tratamento?" (p.59). Para tal, inicia uma retomada da estruturação do sujeito, a qual possui uma lógica que se coloca intimamente relacionada com o método de abordagem do sujeito, especialmente, como destaca Vorcaro, quando tratamos crianças nas condições em que a holófrase lhes impõe ou, dito de outro modo, nas condições que as graves psicopatologias lhes impõem.

Com base em uma proposta lacaniana, a autora aponta que as operações implicadas na estruturação do ser em sujeito estão no campo da linguagem, concepção abordada, de alguma maneira, no capítulo anterior. Assim, compartilha com Lacan a hipótese de que a constituição de sujeito se dá numa espécie de trama tecida das sobreposições das dimensões do Real, Simbólico e Imaginário, cada uma compondo 
uma linha infinita ou um círculo. A criança seria um ponto mergulhado na rede da linguagem, que amarra um organismo irredutível, uma articulação de significantes e uma consistência ideal. A rota desse ponto deve ser traçada (p. 60).

A sobreposição do real do organismo à posição simbólica - que localizava o bebê num campo discursivo antes que ele nascesse - investida imaginariamente pelo agente materno, produz uma certa regularidade de alternância, que opõe tensão e apaziguamento, ao mesmo tempo que articula a descarga orgânica de tensão ao apaziguamento da resposta do agente materno - é o que é vivido como experiência de satisfação. Inaugura-se a condição de subjetivação, a partir da inscrição da articulação da resposta materna à manifestação da necessidade do bebê. (pp. 60-61)

Diversos movimentos de trançamento ocorrem para construção de uma rede que vão sobrepondo e articulando real, simbólico e imaginário. O percurso permite ao sujeito sua inscrição no simbólico, que lhe é pré-existente. Para um melhor entendimento desse percurso, bem como sobre a referência à significação fálica, à operação metafórica do Nome-do-pai, ao objeto "a", à função significante e, enfim, ao desejo, convidamos à leitura inicial desse segundo capítulo em que a autora retoma a constituição subjetiva, a formação do inconsciente, que definiria a condição de criança para a psicanálise.

A partir disso, retomam-se as questões referentes às manifestações da criança e à direção do tratamento, mais precisamente, sobre as perspectivas da interpretação.

Quanto à primeira delas, Vorcaro destaca a importância de localizar a criança na temporalidade de sua estruturação. A criança, por meio dos jogos, narrativas, desenhos, movimentos, através da apresentação na qual seus pais a implicam, sugere sentidos que estariam em função da relação do infans a uma alteridade estruturada (p. 66). Assim, Vorcaro trabalha as "Incidências do fantasma e do sintoma na criança", "O discurso parental: uma das incidências da transferência" e, finalmente, diferentes operações de interpretação na busca de uma aproximação à realidade psíquica da criança. Diversos psicanalistas argentinos, do "Centro Pequeño Hans", e suas abordagens quanto ao lugar da interpretação, suas ressonâncias, finalidades, são referidos nesse momento.

Quanto à direção do tratamento, a autora vai referir-se ao psicanalista Bernard Nominé que, na conferência de junho de 1999 em São Paulo, disse que "Só podemos nos referir aos fins da análise com crianças no plural (...). A relação sexual é fronteira que distingue a experiência sexual infantil da experiência do adulto e o período de latência tem aí grande importância. O uso do plural se deve ao fato de cada caso poder contestar o que são os fins da análise, além do vocábulo poder se referir à saída e ao objetivo" (p. 92). Ao considerar a posição estrutural da infância, a direção da cura no tratamento de crianças difere da do adulto. Considerar as particularidades que o encontro com uma criança na clínica traz, permite ao analista deparar-se, por exemplo, com a pergunta "a quem atender?". E mais, é objetivar, por meio da análise, 
permitir à criança separar-se do sintoma familiar para construir seu próprio sinthome. Mas, como pensar a direção do tratamento na clínica do autismo e das psicoses?

"Lacan nos ensina que o sujeito é a resposta do real ao significante, ou seja, o sujeito é decorrência (efeito e/ou produto) da incidência do simbólico sobre o ser orgânico, acéfalo, puro real" (p. 95). Por isso, destaca a autora, que trata-se, numa análise, analisar as relações do sujeito com o real. No caso de uma criança autista ou psicótica, o sujeito não se destacou do real, o que a mantém na posição de criançaobjeto, criança-gozo. E nesse caso, o analista só pode se alojar no lugar do Outro primordial. Trata-se aqui de uma análise invertida - uma operação que vai do real ao simbólico; diferentemente de quando nos encontramos diante de um sujeito constituído, quando a operação analítica visa a uma travessia do simbólico e do imaginário em direção ao real da pulsão (pp. 96-97). Assim, a direção do tratamento de uma criança não estruturada é a de permitir, pela transferência, a sua estruturação como sujeito, que significa também constituir uma defesa contra o real. Possibilidade que exige, da interpretação nas graves psicopatologias infantis, uma suposição de sujeito, pelo analista, antes mesmo que haja um ali (p. 99). Para trabalhar essas questões na clínica do autismo e das psicoses, a autora remete-se principalmente a Alfredo Jerusalinsky.

Observamos cada vez mais o movimento de psicanalistas para além dos limites do consultório. Qual o lugar do psicanalista numa equipe multidisciplinar? Existiria aqui a possibilidade da psicanálise interrogar as especificidades, os campos conceituais das diferentes disciplinas que compõem uma equipe de configuração multidisciplinar? O que constitui uma prática interdisciplinar? E como a psicanálise se insere aí? Podemos articular o saber da clínica com a elaboração científica? Para refletir sobre essas questões, remetemos à leitura do terceiro capítulo "Sobre a clínica interdisciplinar". Após a apresentação de uma instituição voltada para o trabalho com crianças e adultos que manifestam distúrbios de linguagem e da fala, a autora trabalha a idéia de uma prática institucional capaz de fazer interrogar as teorias e seus diversos especialistas, a partir da potencialidade da clínica mesma e da consideração da singularidade do caso. A apresentação clínica de pacientes exercida por Lacan é lembrada, bem como é descrita a recriação feita da mesma por Jean Bergés na sua experiência clínica com crianças.

$\mathrm{O}$ quarto capítulo refere-se às relações inter-setoriais entre a psicologia e a fonoaudiologia da Clínica de Distúrbios da Comunicação da PUC-SP. Neste serviço, conjugam-se a formação teórica de fonoaudiólogos com a prática do atendimento clínico. "Essa escolha tem o propósito de balizar um campo de deslizamentos de saberes distintos no funcionamento cotidiano de uma prática clínica, para suspender os pontos de coincidência em que tais saberes se encobrem e se iluminam, veiculando discursos sobre a abordagem diagnóstica e terapêutica" (p.117). Seguese a análise de um pequeno fragmento do funcionamento institucional: as origens 
da aproximação da fonoaudiologia ao campo da subjetividade e da psicopatologia, a herança médica da psicologia e da fonoaudiologia, a autonomia da fonoaudiologia quanto ao diagnóstico e encaminhamento a outras áreas, os destinos de uma demanda que pode querer dizer de um mal-estar na clínica fonoaudiológica. Depreende-se desse trabalho uma das idéias referenciais orientadoras desse serviço de que os distúrbios da linguagem, mesmo quando associados a quadros orgânicos ou a limitações do meio social, trazem a marca da posição de um sujeito na língua; os distúrbios da linguagem testemunham o rastro de um sujeito na singularidade de sua inscriçâo no laço discursivo (p.122).

Não por acaso nos parece que o capítulo quinto trata "Da língua e de adolescentes numa escola de surdos". A partir do que podemos nos perguntar: qual a singularidade de inscrição na língua de um sujeito acometido pela impossibilidade de ouvir, ou seja, de um sujeito surdo? O capítulo traz o relato de uma experiência na unidade de uma escola que recebe adolescentes surdos. Os professores se queixam do comportamento dos alunos e solicitam a presença de um psicólogo na sala de aula para resolução, em última instância, das suas dificuldades em realizar a tarefa de ensinar em virtude das dificuldades dos alunos. Com situações familiares que variam desde o quase abandono até o absoluto protecionismo, os adolescentes encontram-se numa posição subjetiva de objetos (p.135). No confronto com a situação de aprendizagem, a posição subjetiva dos alunos incide sobre o método, requerendo, num primeiro momento, reformulações por parte da escola. Entretanto, “... apenas a incidência efetiva de uma língua sobre os alunos permitiu os primeiros balizamentos de uma via passível de ser percorrida com algum sucesso" (p.132). $\mathrm{Na}$ sua condição anterior, esses alunos encontravam-se restritos a uma linguagem dual, privada, sígnica, muitas vezes só reconhecível em seu meio familiar imediato e não submetida a outras leis - “... as da língua, cujo funcionamento está regido pelos seus elementos diferenciais e que só adquirem valor no texto em que se inserem" (p.145). Assim, as suas dificuldades como alunos estão referidas às suas dificuldades subjetivas. Tendo permanecido, na primeira infância e na latência, numa alienação ao semelhante, numa posição de objetos, esses adolescentes chegam à escola numa posição de borda entre a debilidade e a psicose, ou seja, com uma séria lacuna na estruturação subjetiva, uma inscrição simbólica não metaforizada. Suas dificuldades não se referem especificamente à condição adolescente, mas ao enfrentamento da adolescência no organismo desses garotos; adolescência a que não corresponde uma condição subjetiva capaz de suportá-la. (p.145)

Situações como a descrita acima, circunscrita no âmbito escolar, indicando um problema que aos professores incidia sobre sua função - um problema que aos professores se colocava, inicialmente, do lado dos alunos que, como conseqüência, trazia dificuldades à sua tarefa de ensinar--, poderia ter convocado a solicitação de uma intervenção psicopedagógica? A pergunta aqui colocada por nós se formula 
com base na leitura do sexto e último capítulo, intitulado "Práticas clínicas e escolares: o discurso psicopedagógico".

Para a autora, a reflexão que faz neste capítulo relaciona-se à interrogação sobre o incremento e constituição, nos últimos dez anos, de cursos de psicopedagogia em diferentes níveis, do que depreende a necessidade de se perguntar sobre sua especificidade e consistência. Assim, baseando-se na análise de relatos individuais de psicopedagogos sobre suas diversas práticas - diagnóstico, terapêutica e intervenção escolar -, inicia-se o trabalho de pesquisa sobre o discurso psicopedagógico. Coloca-se aqui a problemática da análise das práticas psicopedagógicas ser empreendida do exterior de seu campo, o que, entretanto, auxilia a formular uma questão como ponto de partida: explicitar "o que faz do discurso psicopedagógico um campo de interrogação para o psicanalista" (p. 155). Talvez aqui possamos nos remeter ao título do livro mesmo, no ponto em que toca o "laço social”. Pois como traz Vorcaro: “... a posição de sujeito inconstituído, que qualifica a condição de criança, exige do psicanalista a escuta das polimerizações do discurso social sobre a criança, de modo a poder situar o meio no qual sua subjetivação terá que conquistar inscrição" (p. 155). Existe toda uma tradição escolar orientada a partir de uma determinada função social da criança na modernidade uma posição que visa permitir à civilização a sustentação do ideal de seus ancestrais, perpassado pelo narcisismo parental. Não poucas vezes, a escola se vê diante da resistência de alunos à tarefa pedagógica. Embaraços, dificuldades... O discurso psicopedagógico organizou-se disposto a enfrentar os limites de uma tradição escolar, o que, deste ponto, interessa ao psicanalista buscar " ... situar a novidade que o discurso psicopedagógico permite e em que medida ele tem podido superar os impasses causados pela escola" (p. 157). A autora, então, parte para uma apresentação de diferentes aspectos que situaremos como constituintes e caracterizadores do discurso em questão.

Dos relatos realizados pelos psicopedagogos, destacam-se os termos sujeito, aprendizagem e psicopedagogia, evocados, segundo a autora, como conceitos transparentes e fundantes da mesma. Diferentes articulações teóricas são feitas, explicadas em função de seus sujeitos-alvo, demonstrando a impossibilidade da psicopedagogia trabalhar isoladamente as singularidades de sujeitos diante do aprender e, por fim, definindo diferentes modos de aproximação à dificuldade de aprendizagem. Duas questões, no entanto, são privilegiadas para discussão: a relação causalidade e terapêutica dos problemas de aprendizagem e a posição assumida pelo psicopedagogo. Com relação à primeira, Vorcaro vai trabalhar os diferentes modelos causais prevalentes nas dificuldades de aprendizagem e definidores da escolha terapêutica; a avaliação psicopedagógica - definindo o conceito de sintoma, de diagnóstico e realizando uma inicial articulação entre a psicopedagogia e a psicanálise, bem como distinguindo o sujeito epistêmico de Piaget e o sujeito do inconsciente de Freud; o 
“dado" psicopedagógico; a demanda de terapia psicopedagógica; a supervisão; o desenvolvimento cognitivo e a constituição subjetiva - Piaget e Freud. Com relação à segunda questão, da posição do psicopedagogo, mais especificamente, da sua posição na relação com a criança, Vorcaro retoma muitas idéias de Freud e Piaget, convocando o leitor para que se detenha mais nas obras desses autores, capazes de trazerem interrogações que se atualizam, hoje, em cada prática. Para concluir, entre outras questões, sublinha-se o enfrentamento necessário de duas: "O que é aprender? Quais as condições de possibilidade da aprendizagem?" (p. 196).

"Crianças na psicanálise" termina, então, com esse importante capítulo referente, antes de mais nada, ao aprender - às dificuldades relativas ao mesmo. Aprender que perpassa o sujeito do início ao fim de sua vida. Aprender que se constrói.

Talvez seja a hora, agora, de retornarmos ao início do livro em que a autora pergunta sobre a posição desta especificidade clínica - com crianças - relativa à clínica psicanalítica e à formação do analista. Disso sublinhamos a importância da leitura de um livro como esse aos psicanalistas e não somente a aqueles que tratam de crianças. Afinal, elas remetem ao 'infantil' e ao processo de constituição do sujeito - material precioso para escuta a de qualquer psicanalista. 